\title{
Sensibilidade de Metarhizium anisopliae à temperatura e umidade em três tipos de solos
}

\author{
Sensibility of Metarhizium anisopliae to temperature and moisture in three soil types
}

Lourenço Maurício Lanza' Antonio Carlos MonteiroII Euclides Braga Malheiros ${ }^{\text {III }}$

\section{RESUMO}

Este trabalho teve como objetivo investigar o efeito da temperatura e do teor de umidade do solo na sobrevivência de Metarhizium anisopliae (Metsch.) Sorok. em três tipos de solos. Foram utilizados o Latossolo Vermelho textura argilosa, Latossolo Vermelho textura média e Argissolo Vermelho Amarelo textura arenosa média. As temperaturas empregadas foram 21,5; 26,8 e $31,5^{\circ} \mathrm{C}$, e os teores de umidade foram 35 , 65 e 100\% de saturação. A sobrevivência do fungo foi avaliada após zero, 20, 40, 60, 80, 100 e 120 dias de incubação em cada temperatura estudada. Na análise do efeito do teor de umidade, a sobrevivência foi avaliada após zero, 14, 28, 42, 56, 70, 84, 98 e 112 dias de incubação à temperatura de $27,0 \pm 1,0^{\circ} \mathrm{C}$. Em ambos os ensaios, foi determinado o número de unidades formadores de colônias (UFC) em placa de Petri. Houve influência significativa da temperatura e do teor de umidade na sobrevivência do fungo. O maior crescimento e a maior sobrevivência ocorreram nas temperaturas de 21,5e $26,8^{\circ} \mathrm{C}$, enquanto que, no solo incubado a $31,5^{\circ} \mathrm{C}$, o fungo cresceu pouco, e a população declinou rapidamente. No teor de $65 \%$ de umidade, houve rápido crescimento do fungo, mas no $112^{0}$ dia foi observado um declínio da população nos três tipos de solos. Nos teores de 35 e 100\% de umidade, o crescimento foi menor, mas obteve-se maior sobrevivência do fungo no solo.

Palavras-chave: controle biológico, controle microbiano, ecologia, fungo entomopatogênico.

\section{ABSTRACT}

The aim of this research was to evaluate the effect of soil temperature and soil water saturation on Metarhizium anisopliae survival in three soil types. The fungus survivorship was determined in the following soils types: Oxissol with clay texture, Oxissol with medium texture and Alfissol with medium sandy texture. The temperatures tested were 21.5; 26.8 and $31.5^{\circ} \mathrm{C}$ and the soil water saturation were 35,65 and $100 \%$. The fungus survivorship was evaluated at zero, 20, 40, 60, 80, 100, 120 days after soil incubation in each temperature accessed. In the assay for water saturation studies, the survival was evaluated after zero, 14, 28, 42, 56, 70, 84, 96, 112 days of incubation at $27.0 \pm 1.0^{\circ} \mathrm{C}$. In both the assays, the colonies forming units (CFU) was determined in Petri dishes. The fungus survival was significantly influenced by the soil temperature and soil moisture. An increase in the number of CFU was observed in soil held at 26.8 and $21.5^{\circ} \mathrm{C}$. The highest temperature $\left(31.5^{\circ} \mathrm{C}\right)$ was more detrimental to fungus growth and survival than the lowest ones. The fungus grew quickly in the $65 \%$ soil water saturation but afterwards a decrease in the soil fungal population in the three soil types was observed. The 35 and 100\% soil water saturations favored the fungus survivorship in the soil but was less favorable for the fungus growth.

Key words: biological control, microbial control, ecology, entomopathogenic fungus.

\section{INTRODUÇÃO}

O uso de fungos como bioinseticidas, em substituição aos produtos químicos, vem se intensificando nos últimos anos (PEREIRA et al., 1998), a partir de populações naturais e melhoradas (ALVES, 1998). Esses microrganismos já exercem a função de controle de insetos em ambientes naturais, ocupando

'Programa de Pós-graduação em Microbiologia Agropecuária, Faculdade de Ciências Agrárias e Veterinárias (FCAV), Universidade Estadual Paulista (UNESP), Jaboticabal, SP, Brasil. E-mail: lmlanza@terra.com.br.

IIDepartamento de Produção Vegetal, FCAV, UNESP. Via de Acesso Prof. Paulo Donato Castellane, s/n, 14884-900, Jaboticabal, SP, Brasil. E-mail: montecar@fcav.unesp.br. Autor para correspondência.

IIIDepartamento de Ciências Exatas, FCAV, UNESP, Jaboticabal SP, Brasil. 
um lugar relevante na manutenção do equilíbrio ecológico, mas sofrem a influência tanto de fatores bióticos, do ambiente quanto abióticos. O efeito fungistático promovido pela microbiota do solo tem sido apontado por vários autores como um dos principais fatores bióticos que afetam a sobrevivência dos fungos entomopatogênicos (LINGG \& DONALDSON, 1981; SHIELDS et al., 1981; GRODEN \& LOCKWOOD, 1991).

Dentre os fatores abióticos, a temperatura, a umidade e o tipo de solo, isoladamente ou em combinação, podem afetar a persistência do conídio, a mortalidade do hospedeiro e a esporulação do fungo sobre o cadáver do inseto. A temperatura afeta a persistência do conídio e a mortalidade de insetos subterrâneos expostos ao fungo (RATH, 2002). Temperaturas baixas ou medianas e valores intermediários de saturação do solo favorecem a sobrevivência dos conídios (LINGG \& DONALDSON, 1981), enquanto altas temperaturas e teores de saturação elevados reduzem a sobrevivência (STUDDERT \& KAYA, 1990b). A umidade do solo é também um fator limitante para a aplicação de formulações miceliais de fungos entomopatogênicos (RATH, 2002). Entretanto, poucos foram os trabalhos que investigaram o efeito da temperatura e umidade do solo na sobrevivência de fungos entomopatogênicos. Além disso, os resultados não são conclusivos.

Beauveria bassiana (Bals.) Vuill. não formou colônias ou produziu conídios na superfície de cadáveres de Spodoptera exigua Hübner em solo com $86 \%$ de umidade, mas a $97 \%$ e em solo saturado houve a formação de colônias. A temperatura de $24^{\circ} \mathrm{C}$ proporcionou o maior crescimento, mas não houve diferença significativa quando o fungo cresceu a 13, 20 e $28^{\circ} \mathrm{C}$, em qualquer combinação com o teor de umidade (STUDDERT \& KAYA, 1990a). A sobrevivência de conídios de $\boldsymbol{B}$. bassiana foi afetada adversamente pelo aumento da temperatura e do teor de umidade de um solo argiloso não-esterilizado, em um período de duas semanas (KRUEGER et al., 1991). Resultado semelhante foi obtido por QUINTELA et al. (1992), que observaram redução da sobrevivência de conídios de $\boldsymbol{B}$. bassiana em terra roxa estruturada latossólica eutrófica em função do aumento da temperatura $\left(17,24\right.$ e $30^{\circ} \mathrm{C}$ ) e saturação do solo (25 e $75 \%)$.

Analisando o potencial matricial do solo (de 0 a -16 KPa) na esporulação e sobrevivência de dois isolados de $\boldsymbol{M}$. anisopliae, LI \& HOLDOM (1993) verificaram que, em solos mais úmidos ( 0 a -2,0 KPa), ocorreu redução mais rápida da sobrevivência do que em solos moderadamente secos (-10 a -16KPa), tendo sido observado efeito significativo do potencial matricial na sobrevivência dos conídios aos 30 dias, no solo argiloso, e aos 60 dias, no solo areno-argiloso. No solo argiloso, o isolado M703 produziu mais conídios a -10KPa, mas a maior esporulação ocorreu em solo areno-argiloso a $-15 \mathrm{KPa}$. Ao estudarem o efeito da temperatura $\left(15,20,25\right.$ e $\left.30^{\circ} \mathrm{C}\right)$ e umidade (-0,1 e -0,0035MPa) na sobrevivência e infectividade de quatro isolados de $\boldsymbol{M}$. anisopliae sobre pupas de quatro espécies de moscas do gênero Ceratitis, em um solo areno-argiloso, EKESI et al. (2003) encontraram grande variação nas respostas obtidas para os isolados. De acordo com LANZA et al. (2004), o tipo de solo e o grau de compactação influenciam a sobrevivência de M. anisopliae no solo, sendo favorecida no solo com textura areno-argilosa e quando o solo é pouco compactado.

O solo é o reservatório natural de fungos que infectam insetos. A eficiência do controle por eles exercido sobre insetos no ambiente natural ou no agroecossistema pode depender, dentre outras características, de sua sobrevivência e atividade em condições ambientais compatíveis. Assim sendo, os fatores que atuam nas populações de fungos entomopatogênicos no solo necessitam ser mais bem conhecidos. Desse modo, o presente trabalho objetivou estudar a influência da temperatura e do teor de umidade do solo na sobrevivência do fungo $\boldsymbol{M}$. anisopliae, em três tipos de solos.

\section{MATERIAL E MÉTODOS}

Foi utilizado o isolado E9 de M. anisopliae, obtido de Deois flavopicta Stal (cigarrinha-daspastagens), mantido em cultura estoque a $4^{\circ} \mathrm{C}$, na coleção do laboratório de Microbiologia, do Departamento de Produção Vegetal, da Faculdade de Ciências Agrárias e Veterinárias (FCAV), da Universidade Estadual Paulista (Unesp). Colônias do fungo cultivadas em BDA a $27 \pm 0,5^{\circ} \mathrm{C}$ por 15 dias foram usadas para o preparo de suspensões, transferindose conídios da superfície para tubos contendo uma mistura (1:1) de solução salina de $\mathrm{NaCl}$ a $0,89 \%\left(\mathrm{p} \mathrm{v}^{-1}\right)$ e solução de Tween $80^{\circledR}$ a $0,1 \%\left(\mathrm{v} \mathrm{v}^{-1}\right)$. Após contagem em câmara de Neubauer, foram padronizadas as concentrações das suspensões em 2,0 x $10^{7}$ conídios $\mathrm{mL}^{-1}$.

Foram utilizados os seguintes solos: Latossolo Vermelho textura argilosa [53\% de argila, 18\% de silte, 29\% de areia e 3,5\% de matéria orgânica (M O)], coletado em propriedade agrícola no Distrito de Lusitânia, Município de Jaboticabal, São Paulo, (SP) ( $21^{\circ} 07^{\prime} 04^{\prime \prime} \mathrm{S}$; $\left.48^{\circ} 16^{\prime} 44^{\prime \prime} \mathrm{W}\right)$; Latossolo Vermelho textura 
média (27\% de argila, $9 \%$ de silte, $64 \%$ de areia e $2 \%$ de M O), coletado próximo ao cruzamento das rodovias SP 326 e SP 333, Município de Jaboticabal, SP (21 $17^{\prime}$ $00^{\prime \prime} \mathrm{S} ; 48^{\circ} 20^{\prime} 00^{\prime \prime} \mathrm{W}$ ) e um Argissolo Vermelho Amarelo textura arenosa média (15\% de argila, 7\% de silte, $78 \%$ de areia e $2,6 \%$ de $\mathrm{M}$ O), coletado em propriedade agrícola do Município de Monte Alto, SP (21 $21^{\prime} 02^{\prime \prime}$ $\left.\mathrm{S} ; 48^{\circ} 31^{\prime} 17^{\prime \prime} \mathrm{W}\right)$. Depois de coletados, os solos foram secos em temperatura ambiente, destorroados e peneirados em malha de $1 \mathrm{~mm}$, e armazenados em sacos de plástico até a utilização. As características físicas e químicas de cada tipo de solo foram determinadas pelo laboratório do Departamento de Solos e Adubos da FCAV/Unesp e a capacidade de saturação foi determinada antes de cada ensaio.

Os ensaios foram realizados com cinco placas de Petri (repetições) por tratamento, contendo, cada placa, $80 \mathrm{~g}$ de solo. Em toda a extensão da face interna da tampa da placa, foram fixados, com fita adesiva, dois palitos de madeira para facilitar as trocas gasosas. Depois de pesadas, as placas foram envoltas em conjunto de três com dupla folha de papel e autoclavadas a $121^{\circ} \mathrm{C} \mathrm{e} 1 \mathrm{Kgf} \mathrm{cm}^{-2}$ durante 60min.

No ensaio conduzido para avaliar o efeito da temperatura, depois de autoclavados, os solos contidos nas placas receberam, em ambiente asséptico, água destilada esterilizada em quantidade suficiente para atingir $65 \%$ de saturação. Após repouso por três horas para estabilização, o solo recebeu $2 \mathrm{~mL}$ de uma suspensão de 2,0 x $10^{7}$ conídios $\mathrm{mL}^{-1}$, distribuída por toda a superfície do mesmo. Em seguida, as placas foram mantidas nas temperaturas de $21,5 \pm 0,5^{\circ} \mathrm{C} ; 26,8 \pm 0,5^{\circ} \mathrm{C}$ e $31,5 \pm 0,5^{\circ} \mathrm{C}$. Essas temperaturas foram determinadas de acordo com os dados fornecidos pela estação meteorológica da FCAV- Unesp, Jaboticabal (SP), em solo nu, avaliado na camada de 0 a $20 \mathrm{~cm}$ de profundidade. Essas temperaturas foram escolhidas por representarem, respectivamente, valores médios obtidos no local, nos meses de julho (inverno), abril e setembro (outono e primavera), e janeiro (verão), durante os anos de 2000 e 2001. Recipientes com água foram colocados no interior das estufas, para manter o ambiente úmido. As placas foram pesadas semanalmente e, considerando o peso inicial acrescido do peso da água usada para umidificação e a contida no inóculo, a água perdida foi reposta, mantendo-se o teor de saturação do solo em 65\%.

No ensaio efetuado para avaliar o efeito do teor de umidade, os solos contidos nas placas receberam, em ambiente asséptico, água destilada esterilizada em quantidade suficiente para atingir 35, 65 e 100\% de saturação de água no solo. Cinco placas com cada um dos tipos de solo, para cada teor de umidade, foram acondicionadas ao acaso no interior de caixas de plástico (volume da caixa: 7000mL). Em cada caixa foi adaptado um higrômetro para observação diária da umidade relativa do ar no seu interior. Dentro da caixa contendo os solos com teor de $100 \%$ de umidade, foi colocado um recipiente com água. Todo o procedimento foi realizado em câmara asséptica e, após vedação hermética, as caixas permaneceram em estufa a $27 \pm 1^{\circ} \mathrm{C}$. Quando eram retiradas amostras para a avaliação, a água perdida pelo solo em cada placa era reposta. As menores e as maiores porcentagens de água reposta em cada tipo de solo, considerando todos os teores de umidade e ocasiões, foram respectivamente: solo argiloso: 1 e 3,9\%; solo textura média: 1 e 6,3\%; solo textura arenosa média: 1 e 6,8\%.

Para avaliar a sobrevivência do fungo, uma amostra de 1,0g de solo úmido, composta de 15 a 20 subamostras colhidas na superfície de cada placa, foi suspendida em $9 \mathrm{~mL}$ de solução aquosa de Tween $80^{\circledR}$ a $0,1 \%(v / v)$. A partir dessa suspensão inicial, foram feitas diluições seriadas, adequando-se o título das diluições decimais em cada avaliação, de acordo com a perspectiva de aumento ou redução da quantidade de UFC (Unidades Formadoras de Colônias) no solo, em função do tempo de incubação. Em seguida, foi semeado $0,1 \mathrm{~mL}$ da suspensão em placas de Petri contendo 20mL do meio de cultura de JOUSSIER \& CATROUX (1976), modificado pela supressão do suco de legumes e oxgall. Para cada amostra de solo, foram semeadas três placas de Petri das diluições com maior expectativa de obter a quantidade de 30 a 300UFC por placa de Petri. As placas foram mantidas em estufa a $27 \pm 1^{\circ} \mathrm{C}$, no escuro, e o número de UFC, em cada placa, foi determinado até o 5 o dia de incubação. No ensaio do efeito da temperatura, as avaliações foram realizadas nos tempos zero, 20, 40, 60, 80, 100 e 120 dias de incubação, enquanto no estudo do teor de umidade os tempos de avaliação foram de zero, 14, 28, 42, 56, 70, 84, 98 e 112 dias incubação.

Os ensaios foram organizados segundo o delineamento inteiramente casualizado. A análise dos dados foi realizada de acordo com o delineamento em parcelas subdivididas, com nove tratamentos principais (três temperaturas $x$ três tipos de solo, no ensaio de temperatura, e três teores de umidade $\mathrm{x}$ três tipos de solo, no ensaio de umidade do solo), tendo como tratamentos secundários as épocas de avaliação (sete épocas no ensaio de temperatura e nove épocas no ensaio de umidade do solo). A análise de variância foi realizada por meio do teste $\mathrm{F}$, e as médias foram comparadas pelo teste de Tukey a 5\% de probabilidade de erro. Para a execução das análises, foi utilizado o procedimento GLM do programa SAS, versão 6.12. 


\section{RESULTADOS E DISCUSSÃO}

A temperatura teve influência significativa $(\mathrm{P}<0,01)$ na sobrevivência de $\boldsymbol{M}$. anisopliae ao longo do tempo nos três tipos de solos utilizados. Verificouse, também, efeito significativo $(\mathrm{P}<0,01)$ das várias interações entre temperatura, tipo de solo e tempo de incubação, mostrando que houve influência do tipo de solo e da interação temperatura-solo na sobrevivência do fungo. As temperaturas de 21,5 e $26,8^{\circ} \mathrm{C}$ proporcionaram maior sobrevivência do fungo, mostrando tendência similar em relação aos três tipos de solos e diferindo acentuadamente da sobrevivência verificada na temperatura de $31,5^{\circ} \mathrm{C}$ (Figura 1 A, B e C). Nas duas primeiras temperaturas, o crescimento do fungo nos solos argiloso e de textura média foi muito semelhante até o $60^{\circ}$ dia, a partir do qual se observou um pequeno decréscimo no número de UFCs (Figura 1 A, B). No solo arenoso, incubado na temperatura de $21,5^{\circ} \mathrm{C}$, o fungo cresceu até o $120^{\circ}$ dia (Figura 1 C).

A incubação do fungo na temperatura de $31,5^{\circ} \mathrm{C}$ promoveu pequeno crescimento em todos os tipos de solos, apenas até o $20^{\circ}$ dia. Depois disso, houve um declínio acentuado na população e, no $120^{\circ}$ dia, a quantidade de UFCs recuperadas foi inferior àquela verificada na avaliação inicial, indicando que nessa condição o ambiente edáfico se torna restritivo para a sobrevivência do fungo (Figura 1 A, B e C). A incubação no solo textura arenosa na temperatura de $21,5^{\circ} \mathrm{C}$ proporcionou ao fungo o crescimento mais estável (Figura 1C), mas os maiores valores de UFCs foram obtidos nessa mesma temperatura, no solo de textura média (Figura 1B).

A ação da temperatura na concentração e eficácia de fungos no solo é variável e parece estar positivamente relacionada à taxa de crescimento ótimo da espécie ou linhagem em investigação (KRUEGER \& ROBERTS, 1997). De acordo com esses autores, o solo é considerado um ambiente favorável para o uso de fungos como agentes de controle biológico, porque oferece proteção contra a radiação solar e as flutuações extremas de temperatura.

Os resultados obtidos neste trabalho mostraram que, nos três tipos de solos, as menores temperaturas favoreceram o crescimento e a sobrevivência do fungo. Além disso, a maior temperatura restringiu acentuadamente sua sobrevivência, resultados também observados por QUINTELA et al. (1992). De acordo com SOSA-GOMEZ \& MOSCARDI (1994), a baixa temperatura do solo sob mínima aração pode ter contribuído para a alta incidência de $\boldsymbol{B}$. bassiana, $\boldsymbol{M}$. anisopliae e Paecilomyces spp, em comparação ao solo arado.

M. anisopliae foi encontrado no solo um ano após sua aplicação (GLARE et al., 1994). Amostra desse solo incubada a $20^{\circ} \mathrm{C}$ produziu
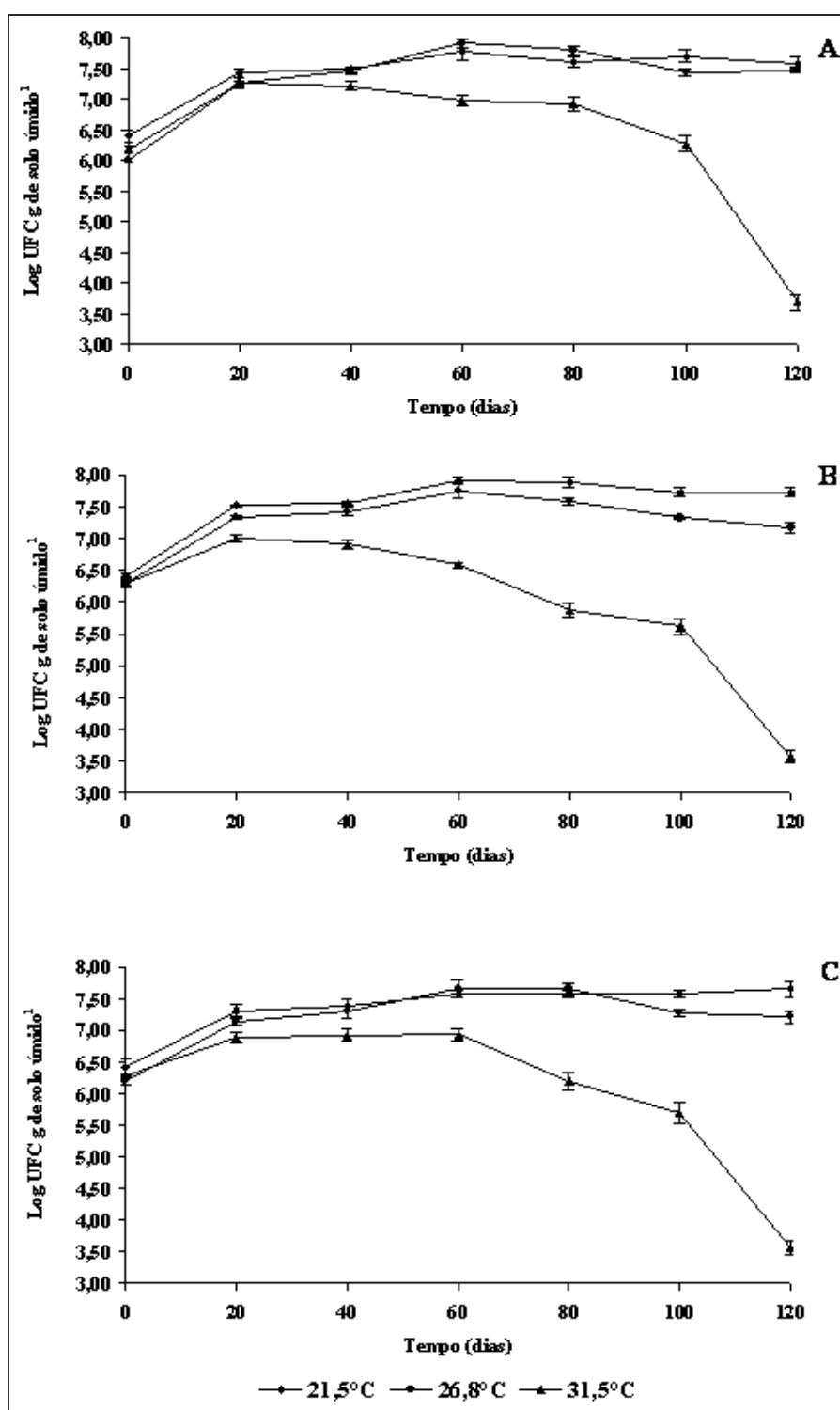

Figura 1 - Sobrevivência de Metarhizium anisopliae em três temperaturas $\left({ }^{\circ} \mathrm{C}\right)$ e tipos de solo. A: Latossolo Vermelho textura argilosa; B: Latossolo Vermelho textura média; C: Argissolo Vermelho Amarelo textura arenosa média.

Ciência Rural, v.39, n.1, jan-fev, 2009. 
mortalidade de larvas de Costelytra zealandrica White, enquanto em uma amostra incubada a $15^{\circ} \mathrm{C}$ não ocorreu mortalidade de larvas, indicando a necessidade de temperatura adequada para a atividade do fungo. Após aplicarem conídios de B. bassiana e M. anisopliae no solo para o controle de larvas de Chalcodermus bimaculatus Boh. em caupi, QUINTELA et al. (1994) verificaram que, na menor temperatura do solo, houve ação mais efetiva dos fungos e a atividade de $\boldsymbol{M}$. anisopliae permaneceu estável por mais tempo. Os autores comentaram que altas temperaturas, verificadas no solo de algumas regiões onde foram conduzidos os experimentos, podem ter contribuído para oscilações na atividade do fungo.

Esporos do isolado A6 de $\boldsymbol{B}$. bassiana sobreviveram melhor no solo a 10 e $15^{\circ} \mathrm{C}$, com a densidade mantendo-se estável por mais de 123 dias nos teores de 13,23 e $30 \%$ de umidade, enquanto a $20^{\circ} \mathrm{C}$ a taxa de declínio da população variou significantemente de acordo com o teor de umidade do solo (O'CALLAGHAN et al., 2001). EKESI et al. (2003) demonstraram que tanto a temperatura, quanto a umidade influenciaram a sobrevivência e infectividade de $\boldsymbol{M}$. anisopliae para quatro espécies de moscas-das-frutas do gênero Ceratitis. De acordo com KESSLER et al. (2003), temperaturas entre 20 e $25^{\circ} \mathrm{C}$ e alto conteúdo de argila no solo tiveram efeito positivo na ocorrência e densidade de Beauveria brongniartii (Sacc.) Petch, enquanto temperatura acima de $27^{\circ} \mathrm{C}$ teve efeito negativo.

O crescimento do fungo foi significativamente influenciado $(\mathrm{P}<0,01)$ pelo teor de umidade, pelo tipo de solo, pelo tempo de incubação e pelas diferentes interações entre esses fatores. Esses resultados evidenciaram que o teor de umidade pode desempenhar um papel importante no crescimento e na sobrevivência do fungo no solo. O crescimento do fungo foi bastante afetado pela interação entre o teor de umidade e o tipo de solo, tendo o solo com textura arenosa propiciado as melhores condições para o crescimento nos três teores de umidade. No teor de $65 \%$ de umidade, houve rápido crescimento do fungo até $28^{\circ}$ dia em todos os tipos de solos. Em seguida, ocorreu uma variação no crescimento, mas no $112^{\circ}$ dia a população do fungo declinou nos três tipos de solos (Figura 2 A, B e C). No teor de 100\% de umidade, o maior crescimento foi obtido no $84^{\circ}$ dia, no solo textura argilosa (Figura $2 \mathrm{~A}$ ), e no $70^{\circ}$ dia, no solo arenoso (Figura $2 \mathrm{C}$ ). No teor de $35 \%$ de umidade, isso ocorreu no solo arenoso, no 84 dia após a inoculação (Figura $2 \mathrm{C}$ ). Entretanto, em ambos os casos, a partir daí houve um declínio na população do fungo no solo. No $112^{\circ}$ dia de incubação, a densidade populacional do fungo em cada tipo de solo foi muito semelhante, considerando os três teores de umidade analisados (Figura 2A, B e C).

Junto com a temperatura, o teor de umidade tem sido apontado por vários autores como um dos principais fatores que afetam o crescimento e a
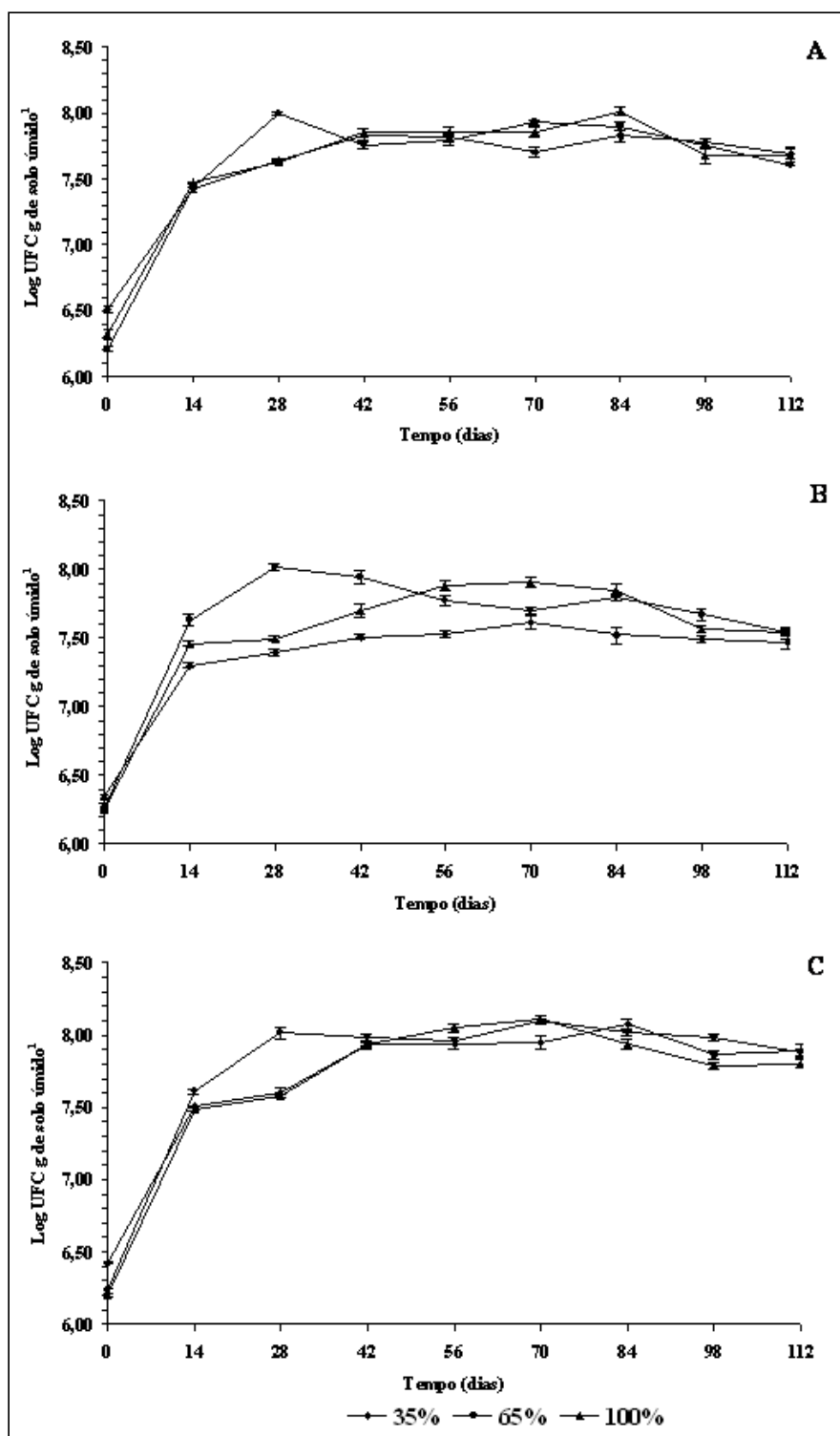

Figura 2 - Sobrevivência de Metarhizium anisopliae em três teores de umidade e tipos de solo. A: Latossolo Vermelho textura argilosa; B: Latossolo Vermelho textura média; C: Argissolo Vermelho Amarelo textura arenosa média.

Ciência Rural, v.39, n.1, jan-fev, 2009. 
sobrevivência de fungos entomopatogênicos no solo (STUDDERT et al., 1990; STUDDERT \& KAYA, 1990a eb; LI \& HOLDOM, 1993; EKESI et al., 2003). IGNOFFO (1992) destacou que a umidade é um requisito fundamental para a germinação de conídios e sobrevivência de fungos entomopatogênicos. A esporulação do fungo é adversamente afetada pelo alto conteúdo de umidade (LI \& HOLDOM, 1993), e isso também acontece com a sobrevivência dos conídios (LINGG \& DONALDSON, 1981; STUDDERT et al., 1990). De acordo com KELLER \& BIDOCHKA (1998), solo com umidade reduzida pode contribuir para o decréscimo na abundância de fungos. KRUEGER \& ROBERTS (1997) reportaram-se ao solo como um ambiente favorável ao uso de fungos entomopatogênicos devido à umidade alta e estável.

Os resultados obtidos neste trabalho indicam que o crescimento do fungo foi favorecido pelo teor de $65 \%$ de umidade, independentemente do tipo de solo, achado semelhante ao obtido por LINGG \& DONALDSON (1981), STUDDERT \& KAYA, 1990b e LI \& HOLDOM (1993). Contudo, observou-se um rápido declínio na população do fungo, no solo textura média com $65 \%$ de umidade. Nos solos com 35 e $100 \%$ de umidade, o fungo cresceu mais lentamente, mas foi verificada maior estabilidade na sobrevivência ao longo do tempo. Os resultados sugerem também a ocorrência de uma relação entre o conteúdo de umidade e o tipo de solo, pois, no solo de textura média foi observado crescimento mais lento e menor sobrevivência do fungo nos três teores de umidade.

\section{CONCLUSÃO}

A sobrevivência de $\boldsymbol{M}$. anisopliae é influenciada pela temperatura e pelo teor de umidade do solo. Alta temperatura $\left(31,5^{\circ} \mathrm{C}\right)$ dificulta o crescimento e a sobrevivência de $\boldsymbol{M}$. anisopliae, enquanto temperaturas menores $\left(26,8\right.$ e $\left.21,5^{\circ} \mathrm{C}\right)$ favorecem o crescimento e a sobrevivência do fungo no solo. O teor de $65 \%$ de saturação do solo favorece o rápido crescimento do fungo.

\section{REFERÊNCIAS}

ALVES, S.B. Fungos entomopatogênicos. In: ALVES, S.B. (Ed.). Controle microbiano de insetos. 2.ed. Piracicaba: FEALQ, 1998. Cap.11, p.289-381.

EKESI, S. et al. Effect of soil temperature and moisture on survival and infectivity of Metarhizium anisopliae to four tephritid fruit fly puparia. Journal of Invertebrate Pathology, San Diego, v. 83, n.2, p.157-167, 2003.
GLARE, T.R. et al. Temperature limitations on field effectiveness of Metarhizium anisopliae against Costelytra zealandica (White) (Coleoptera: Scarabaeidae) in Canterbury, 1994. Capturado em 1 nov. 2003. Online. Disponível em: <http://www.hortnet.co.nz/publications/nzpps/proceedings 94/ 94_266htm>.

GRODEN, E.; LOCKWOOD, J.L. Effects of soil fungistasis on Beauveria bassiana and its relationship to disease incidence in colorado potato beetle, Leptinotarsa decemlineata, in Michigan and Rhode Island soils. Journal of Invertebrate Pathology, San Diego, v.57, n.1, p.7-16, 1991

IGNOFFO, C.M. Environmental factors affecting persistence of entomopathogens. Florida Entomologist, Gainesville, v.75, n.4, p.516-525, 1992.

JOUSSIER, D.; CATROUX, G. Mise au point d'un milleau de culture pour le denombrement de Beauveria tenella dans le sols. Entomophaga, Paris, v.21, n.3, p.223-225, 1976.

KELLER, L.; BIDOCHKA, M.J. Habitat and temporal differences among soil microfungal assemblages in Ontario. Canadian Journal of Botany, Ottawa, v.76, n.10, p.17981805, 1998.

KESSLER, P. et al. The effect of application time and soil factors on the occurrence of Beauveria brongniartii applied as a biological control agent in soil. Journal of Invertebrate Pathology, San Diego, v.84, n.1, p.15-23, 2003.

KRUEGER, S.R. et al. Infection of chinch bug, Blissus leucopterus leucopterus (Hemiptera: Lygaeidaea), adults by Beauveria bassiana (Deuteromycotina: Hyphomycetes) conidia in soil under controlled temperature and moisture conditions. Journal of Invertebrate Pathology, San Diego, v.58, n.1, p.19-26, 1991.

KRUEGER, S.R.; ROBERTS, D.W. Soil treatment with entomopathogenic fungi for corn rootworm (Diabrotica spp.) larval control. Biological Control, Orlando, v.9, n.1, p.6774, 1997.

LANZA, L.M. et al. População de Metarhizium anisopliae em diferentes tipos e graus de compactação do solo. Ciência Rural, Santa Maria, v.43, n.6, p.1757-1762, 2004.

LI, D.P.; HOLDOM, D.G. Effect of soil matric potential on sporulation and conidial survival of Metarhizium anisopliae (Deuteromycotina: Hyphomycetes). Journal of Invertebrate Pathology, San Diego, v.62, n.3, p.273-277, 1993.

LINGG, A.J.; DONALDSON, M.D. Biotic and abiotic factors affecting stability of Beauveria bassiana conidia in soil. Journal of Invertebrate Pathology, San Diego, v.38, n.2, p.191-200, 1981.

O’CALLAGHAN, M. et al. Effect of soil moisture and temperature on survival of microbial control agents. New Zealand Plant Protection, Palmerston North, v.54, n.1, p.128-135, 2001.

PEREIRA, R.M. et al. Utilização de entomopatógenos no manejo integrado de pragas. In: ALVES, S.B. (Ed.). Controle microbiano de insetos. 2.ed. Piracicaba: FEALQ, 1998. Cap.38, p.1097-1118. 
QUINTELA, E.D. et al. Aplicação de conídios de Beauveria bassiana (Bals.) Vuil. e Metarhizium anisopliae (Metsch.) Sor. para controle de larvas de Chalcodermus bimaculatus Boh. (Coleoptera: curculionidae) no solo. Anais da Sociedade Entomológica do Brasil, Itabuna, v.23, n.3, p.367-377, 1994.

QUINTELA, E.D. et al. Persistência de Beauveria bassiana em solos de cerrado e sua interação com microorganismos do solo. Anais da Sociedade Entomológica do Brasil, Itabuna, v.21, n.1, p.69-82, 1992.

RATH, A.C. Ecology of entomopathogenic fungi in field soils. In: INTERNATIONAL COLLOQUIUM ON INVERTEBRATE PATHOLOGY AND MICROBIAL CONTROL, 8., 2002, Foz do Iguaçu, PR. Anais... Foz do Iguaçu: Society for Invertebrate Pathology, 2002. p.65-71.

SAS INSTITUTE INC . SAS/STAT - User's guide: statistic - version 6.12. Cary, 1998. 846p.

SHIELDS, M.S. et al. Identification of a Penicillium urticae metabolite which inhibits Beauveria bassiana. Journal of
Invertebrate Pathology, San Diego, v.38, n.3, p.374-377, 1981.

SOSA-GOMEZ, D.R.; MOSCARDI, F. Effect of till and no-till soybean cultivation on entomopathogenic fungi in the soil. Florida Entomologist, Gainesville, v.77, n.2, p.284-287, 1994.

STUDDERT, J.P. et al. Effect of water potential, temperature, and clay-coating on survival of Beauveria bassiana conidia in a loam and peat soil. Journal of Invertebrate Pathology, San Diego, v.55, n.3, p.417-427, 1990.

STUDDERT, J.P.; KAYA, H.K. Water potential, temperature, and clay-coating of Beauveria bassiana conidia: Effect on Spodoptera exigua pupal mortality in two soil types. Journal of Invertebrate Pathology, San Diego, v.56, n.3, p.327-336, 1990a.

Water potential, temperature, and soil type on the formation of Beauveria bassiana soil colonies. Journal of Invertebrate Pathology, San Diego, v.56, n.3, p.380-386, 1990b. 